\title{
How to hire helpers? Evidence from a field experiment
}

\author{
Julian Conrads ${ }^{1} \cdot$ Bernd Irlenbusch $^{1}$ • \\ Tommaso Reggiani ${ }^{1} \cdot$ Rainer Michael Rilke $^{1}$. \\ Dirk Sliwka ${ }^{2}$
}

Received: 23 May 2014/Revised: 10 June 2015/Accepted: 22 June 2015

(C) Economic Science Association 2015

\begin{abstract}
How to hire voluntary helpers? We shed new light on this question by reporting a field experiment in which we invited 2859 students to help at the 'ESA Europe 2012' conference. Invitation emails varied non-monetary and monetary incentives to convince subjects to offer help. Students could apply to help at the conference and, if so, also specify the working time they wanted to provide. Just asking subjects to volunteer or offering them a certificate turned out to be significantly more motivating than mentioning that the regular conference fee would be waived for helpers. By means of an online-survey experiment, we find that intrinsic motivation to help is likely to have been crowded out by mentioning the waived fee. Increasing monetary incentives by varying hourly wages of 1, 5, and 10 Euros shows positive effects on the number of applications and on the working time
\end{abstract}

Electronic supplementary material The online version of this article (doi:10.1007/s10683-015-9455-y) contains supplementary material, which is available to authorized users.

Tommaso Reggiani

tommaso.reggiani@uni-koeln.de

Julian Conrads

julian.conrads@uni-koeln.de

Bernd Irlenbusch

bernd.irlenbusch@uni-koeln.de

Rainer Michael Rilke

rainer.rilke@uni-koeln.de

Dirk Sliwka

dirk.sliwka@uni-koeln.de

1 Department of Corporate Development and Business Ethics, University of Cologne, AlbertusMagnus-Platz, 50923 Cologne, Germany

2 Department of Personnel Economics, University of Cologne, Albertus-Magnus-Platz, 50923 Cologne, Germany 
offered. However, when comparing these results with treatments without any monetary compensation, the number of applications could not be increased by offering money and may even be reduced.

Keywords Recruitment · Voluntary work · Monetary incentives · Field experiment

JEL Classification C93 $\cdot$ J33 $\cdot$ M52

\section{Introduction}

How to motivate voluntary helpers? As argued by Menchik and Weisbrod (1987), the standard economic view would suggest to provide financial incentives. Frey and Götte (1999), however, have observed that monetary incentives can undermine motivation: External financial rewards may backfire as extrinsic incentives could crowd out the intrinsic motives to socially engage [see also Deci and Ryan (1985); Bénabou and Tirole 2003, 2006)]. Crowding-out effects are known from different fields of social engagement. Titmuss (1970), for example, argued that monetary compensation for donating blood might crowd out the supply of blood donors [see also Mellström and Johannesson (2008)]. Lacetera et al. (2012), however, have shown that extrinsic financial incentives can also stimulate pro-social behavior, e.g., to donate blood. Thus, the evidence on the crowding effects of financial incentives on pro-social behavior is still inconclusive [see Gneezy et al. (2011) for a critical review].

But there is also some evidence that different forms of non-monetary incentives can motivate individuals. If an action is pro-social per se, individuals may feel motivated by the action itself as they are doing 'good' as shown by Andreoni (1998). Based on the formal analysis of Bénabou and Tirole (2006), Ariely et al. (2009) have shown experimentally that this effect increases if the pro-social activity is observed by others, i.e., people receive social recognition for their actions, improving their social- and self-image [see also Akerlof and Kranton (2000)]. In a similar vein, Kosfeld and Neckermann (2011) presented evidence that nonmonetary awards can have a strong motivating effect. As pointed out by Clary et al. (1998), another non-directly monetary source of motivation are opportunities for personal and professional development, i.e., individuals gain career-related benefits from voluntary work, like learning new skills, being enabled to signal personality traits or improving their personal or business networks [see also Holmström (1999)].

To shed more light on the effects of non-monetary and monetary rewards on the willingness to help, we ran a field experiment in the course of organizing the 'ESA Europe 2012' conference hosted by the University of Cologne. ${ }^{1}$ We recruited helpers to provide technical assistance in each of the presentation rooms of the different parallel sessions. To advertise our search for helpers we sent out 2859

\footnotetext{
1 The conference took place from September 12th-15th, 2012. Conference website: http://www.esa.unikoeln.de
} 
emails to a pool of business and economics students enrolled at the University of Cologne. In the email we varied the types of incentives provided. ${ }^{2}$

In one set of treatments we used three types of incentives that did not involve money. In our baseline treatment we tried to motivate candidates to volunteer by just mentioning that they would have the benefit of attenting the conference during the time they were not working for us. In a second treatment we offered an appreciatory certificate for their service. ${ }^{3}$ In a third treatment we provided information about the exact amount of the regular conference fee, which would be waived for the helpers.

In another set of treatments we provided very small, small and slightly above standard wages to motivate possible candidates, i.e., we offered either 1 Euro, 5 Euros and 10 Euros as an hourly wage. ${ }^{4}$

Subjects were randomly assigned to one of the six treatment groups. Departing from other insightful studies on volunteer work supply that mainly exploit survey data (Frey and Götte 1999) or lab experiments (Linardi and McConnell 2011) and we designed a field experiment [see also Harrison and List (2004)], on the benefits of field experimentation) in line with Gneezy and Rustichini (2000b) and AlUbaydli and Lee (2011). In our analysis we focus on two dependent variables of interest. First, we look at whether possible candidates actually applied to volunteer at the conference with respect to the different treatments. As a second measure we asked applicants, during the application procedure, about the working time he or she is willing to help at the conference. Thus, our experimental design allows us to analyze the effects of different incentive schemes both on the extensive margin (number of applicants) and the intensive margin (working minutes offered).

We find that participants reacted differently to the different types of nonmonetary incentives. Just asking them to volunteer or offering them an additional certificate was significantly more motivating than mentioning that regular attendees would have to pay an expensive registration fee to get access to the conference. One explanation might be that potential helpers were demotivated as their intrinsic motives to help are crowded out when becoming aware that they receive an implicit monetary benefit in terms of a waived fee. To find evidence for this hypothesis, we conduced an additional online-survey experiment. We randomly assigned each survey participant to one of two treatments, showing them either the invitation letter for the waived fee treatment or the baseline treatment in our field experiment. We then asked participants to rate a person who would apply under the given reference letter according to several characteristics. We find that ratings of the applicants' motivation are higher in the baseline treatment, and applicants in the waived fee treatment receive higher ratings for career orientation and status orientation. These results are well in line with an explanation based on the Bénabou and Tirole (2006) model of image concerns: Mentioning the waived fee may have reduced the scope

\footnotetext{
${ }^{2}$ Different from Al-Ubaydli and Lee (2011), we vary the content of the invitation while keeping its format constant.

3 See Kosfeld and Neckermann (2011) and Bradler et al. (2013) for other studies on the impact of certificates.

4 The standard hourly wage for a student assistant is 8.80 Euros at the University of Cologne. We chose the 10 Euros offer since this is a wage for a typical well-paid student job in Cologne.
} 
to signal pro-social motivation and increased the likelihood that an applicant is driven by more selfish reasons. If people value being viewed as pro-social and not too selfish, this reduces the incentive to apply.

Once money was offered, participants were also sensitive to increasing monetary incentives, but only when these incentives were sufficiently strong. While we find no significant differences in the reactions to the 1 Euro or 5 Euros hourly wage, both the number of applications and the working time offered significantly increased when the promised hourly wage was 10 Euros instead of 1 or 5 Euros. Hence, paying more money may actually help to attract helpers, but this does not work when the wage level is substantially below the opportunity costs of work. ${ }^{5}$

Comparing the non-monetary with the monetary incentives, we find no significant effects on both margins between just asking for pure voluntary help compared to offering the 1 Euro or 5 Euros hourly wage. We also do not find significant effects in the extensive margin (i.e., the fraction of applicants) between simply asking for help compared to the 10 Euros treatment. However, there is a significant difference on the intensive margin between these two treatments, i.e., offering a 10 Euros hourly wage significantly increased the working time offered.

Hence, our results give some insights on the question of how to hire "volunteers" that can be applied to other contexts. Of course, the optimal strategy depends on the objective function of the "employer", the size of the applicant pool and the costs of recruiting and training. However, irrespective of these factors, our results indicate that offering small monetary rewards does not help or even becomes detrimental. The question then remains whether and how to appeal to social motives or to offer more generous wages. If, for instance, the available pool of potential applicants is large enough, advertising the position is costless, and the task can be split among more people, our results imply that the "voluntary" announcements as in the baseline condition can work well at low costs. If, however, it is more important to have helpers who offer a sufficient number of hours each (for instance when there are switching costs and costs for training helpers), funds are available, and the applicant pool is restricted or advertising is costly, offering money can be better because social motivation may not guarantee a sufficiently intensive engagement.

The paper proceeds as follows. Section 2 introduces the experimental setup and our six treatments. In Sect. 3 we analyze the data. In Sect. 4 we discuss the main finding and analyze the data from an additional online-survey experiment. Section 5 concludes the paper.

\section{Experimental setup}

We manipulated the emails that were sent out by the organizing committee of the Economic Science Association (ESA) European Conference in Cologne in order to recruit helpers for the conference. A mailing contained basic information about the

\footnotetext{
5 It might well be that working for a price that is lower than the opportunity costs of work leads to a negative self-image and thereby reduces labor supply on top of the mere economic rationale.
} 
dates, topic, and content of the conference. ${ }^{6}$ At the end of the emails we asked recipients the following:

[...] For the preparation and procedure of the conference we are looking for volunteers who support us in the organization before and during the conference. [...]

Students who were interested in helping at the conference were instructed to click on a link to a web page where they were asked to provide some basic information (contact information, demographics) and their availability during the week of the conference. Each day of the conference week was split up into three working shifts of four hours each. Participants who applied had to indicate how many working shifts they would be willing to take.

In our baseline treatment Voluntary only the text mentioned above was included in the email. In the other experimental treatments we added one additional sentence that contained the information about the respective incentives. In a first set of treatments we tested the influence of non-monetary incentives on the probability of applying and the willingness to provide working time. In the treatment Certificate helpers were told that they would receive a formal certificate at the end of the conference to show appreciation for their help. In the treatment Waived Fee we highlighted that the regular conference participation fee of 320 Euros would be waived.

To test the influence of monetary incentives, we devised three additional treatments varying the hourly compensation helpers receive for their service. Although we provided monetary incentives in these treatments, we kept the wording of the emails the same as in the three non-monetary incentive treatments (apart from the sentence which describes the treatment variation). We also continued to use the word volunteer despite the fact that we would pay helpers in the monetary incentive treatments. In the 1 Euro treatment we offered helpers an hourly compensation of one euro and in the 5 Euros and 10 Euros treatments the respective amounts. ${ }^{7}$

For the exact wording of the treatments see Table 1 and for the complete text of the invitation see in the Appendix. Recipients were business and economics students

\footnotetext{
${ }^{6}$ The emails were signed by two professors of the faculty of Management, Economics and Social sciences. The full text can be found in the appendix. The original letters were sent out in German. The German texts are available from the authors upon request.

${ }^{7}$ Before setting up the conference it was not fully clear how many helpers we would actually need. One main task of the helpers was to be present and providing assistance at several parallel conference sessions. In total we had 56 sessions of one and a half hours each. Thus, we needed roughly 86 hours of work for this task. After we received the applications, we hired the applicants from the 10 Euros treatment and paid them accordingly. The authors are aware of the fact that working for a hourly wage might not be considered as "volunteering" and might create cognitive dissonance for potential applicants. In order to keep the invitations as similar as possible between the treatments, we chose to stick to this wording in the invitation email.
} 
Table 1 Treatments

\begin{tabular}{|c|c|c|}
\hline Treatment & Additional sentence describing the treatment variation & $N$ \\
\hline \multicolumn{3}{|c|}{ Non-monetary incentives } \\
\hline Voluntary & - & 477 \\
\hline Certificate & At the end of the conference you will receive a certificate. & 479 \\
\hline Waived Fee & The participation fee which you are exempted from would be about $320 €$. & 469 \\
\hline \multicolumn{3}{|c|}{ Monetary incentives } \\
\hline 1 Euro & Per working hour you get $1 €$. & 484 \\
\hline 5 Euros & Per working hour you get $5 €$. & 473 \\
\hline 10 Euros & Per working hour you get $10 €$. & 477 \\
\hline
\end{tabular}

Notes: $N$ represents the number of observations, i.e., the number of candidates who received an email corresponding to the respective treatment

from the study programs of the Faculty of Management, Economics and Social Sciences at the University of Cologne $\left(44 \%\right.$ female $\left.^{8}\right)$. A total of 2859 emails were sent out two months before the conference. 9

\section{Results}

In the following section we first present the results from our treatments without monetary incentives and then focus on the treatments with monetary incentives.

In Fig. 1 we plot the outcomes by treatment, and in Table 2 we display the descriptive statistics of our two outcome variables of interest. In Fig. 1 the relative frequencies of applications per treatment are displayed in the upper panels (black bars), while the mean minutes of work offered are shown below (gray bars), with the correspondent error bars showing the standard error of the means (dashed bars).

\subsection{Non-monetary incentives}

We start by analyzing the number and frequencies of applications under the different non-monetary treatments.

Observation 1 Mentioning the waived conference fee significantly decreases the number of applications and the hours of work offered.

\footnotetext{
${ }^{8}$ We constructed a dummy variable to classify the gender of each subject according to the first name (in order to recruit helpers for the conference, the central office of the university provided us a simple database containing individual entries about (i) first name, (ii) surname and (iii) email address of the students). The resulting pool of subjects is made up of $44 \%$ of females, $49 \%$ of males and a remaining $7 \%$ classified as gender "missing" since it was not possible to establish with certainty the correct gender of these subjects based on their first name.

9 Before the first mailing, the authors committed to recruit applicants from the treatment with the highest number of applications. The first mailing was sent out on July 6th, followed by two reminders containing the same information on July 26th and August 2nd.
} 

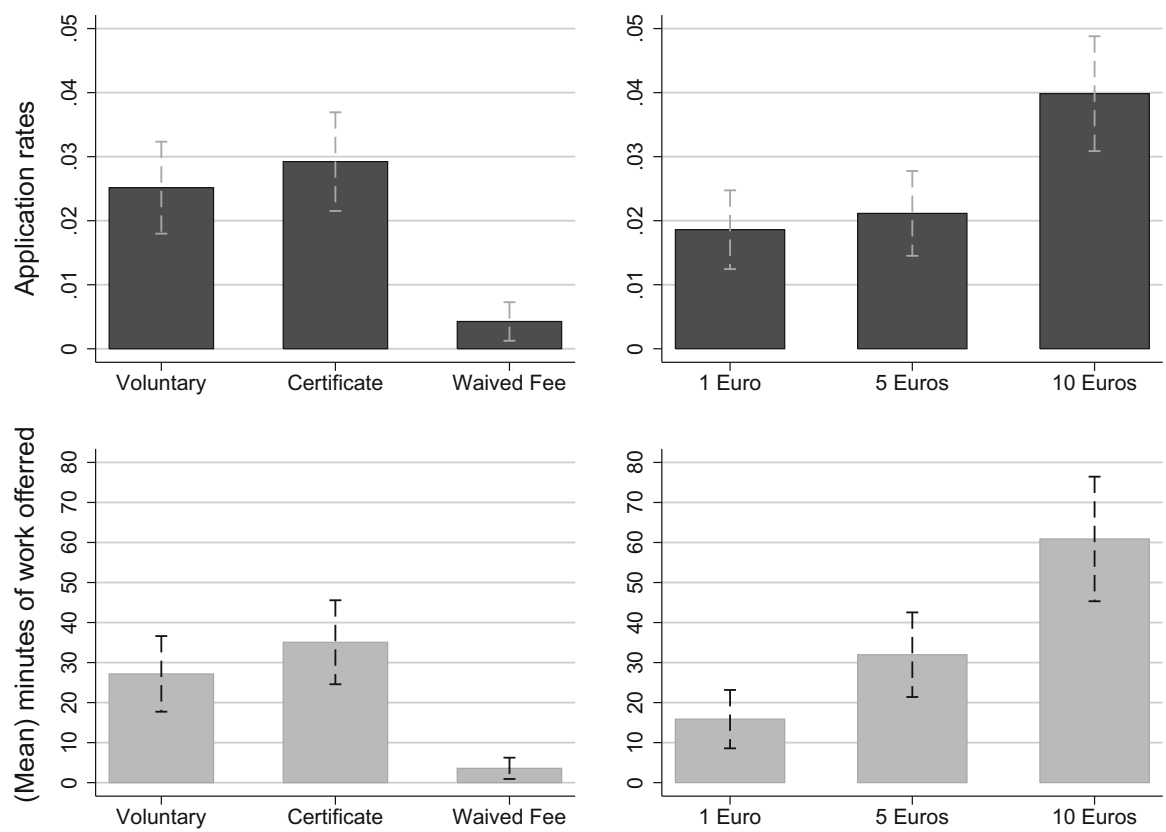

Fig. 1 Upper panel Relative frequencies of applications (black bars) for each experimental treatment. Lower panel Mean minutes of work offered (gray bars) and error bars based on the standard deviations of the means (dashed bars) for each experimental treatment

Table 2 Descriptive statistics of the results

\begin{tabular}{lllllll}
\hline & Voluntary & Certificate & Waived Fee & 1 Euro & 5 Euros & 10 Euros \\
\hline $\begin{array}{l}N-\text { sample size } \\
\text { number of emails }\end{array}$ & 477 & 479 & 469 & 484 & 473 & 477 \\
$\begin{array}{l}\text { Applications } \\
{[\text { rate }]}\end{array}$ & 12 & 14 & 2 & 9 & 10 & 19 \\
Average working minutes & $(2.52 \%)$ & $(2.92 \%)$ & $(0.43 \%)$ & $(1.86 \%)$ & $(2.11 \%)$ & $(3.98 \%)$ \\
(s.d.) & $(206.67$ & 35.07 & 3.07 & 17.36 & 31.97 & 61.38 \\
Average working minutes & 1,100 & $(229.68)$ & $(56.48)$ & $(161.41)$ & $(229.77)$ & $(339.91)$ \\
{$[$ applied $=1] ;$ (s.d.) } & $(748.23)$ & $(658.95)$ & $(678.82)$ & $(781.79)$ & $(531.26)$ & $(805.25)$ \\
Total work minutes & 13,200 & 16,800 & 1,440 & 8,400 & 15,120 & 29,280 \\
\hline
\end{tabular}

The application rate of $0.43 \%$ (2 applications) in the Waived Fee treatment is significantly lower than the application rate of $2.52 \%$ (12 applications) in Voluntary ( $p=.012$, Fisher-test, two-sided). Hence, the waived fee reduced the proportion of applicants by $83 \%$.

No such difference is observed when the Voluntary treatment is contrasted to the application rate of $2.92 \%$ (14 applications) under Certificate ( $p=.843$, Fisher-test, 
Table 3 Regressions for non-monetary incentives

\begin{tabular}{|c|c|c|c|c|c|c|}
\hline \multirow[t]{3}{*}{ Independent variables } & \multicolumn{6}{|c|}{ Dependent variables } \\
\hline & \multicolumn{2}{|c|}{ Applications } & \multicolumn{2}{|l|}{ Minutes } & \multicolumn{2}{|l|}{ Minutes } \\
\hline & (1) & (2) & (3) & (4) & (5) & (6) \\
\hline Certificate & $\begin{array}{l}0.004 \\
(0.01)\end{array}$ & $\begin{array}{l}-0.001 \\
(0.01)\end{array}$ & $\begin{array}{l}7.400 \\
(11.76)\end{array}$ & $\begin{array}{l}-1.330 \\
(11.65)\end{array}$ & $\begin{array}{l}100.000 \\
(275.54)\end{array}$ & $\begin{array}{l}-63.288 \\
(266.31)\end{array}$ \\
\hline Waived Fee & $\begin{array}{l}-0.021^{* *} \\
(0.01)\end{array}$ & $\begin{array}{l}-0.023 * * \\
(0.01)\end{array}$ & $\begin{array}{l}-24.603 * * \\
(11.82)\end{array}$ & $\begin{array}{l}-26.742^{* *} \\
(11.77)\end{array}$ & $\begin{array}{l}-380.000 \\
(534.94)\end{array}$ & $\begin{array}{l}-466.575 \\
(498.46)\end{array}$ \\
\hline Female & & $\begin{array}{l}0.011 \\
(0.01)\end{array}$ & & $\begin{array}{l}2.550 \\
(9.57)\end{array}$ & & $\begin{array}{l}-519.452 * \\
(263.58)\end{array}$ \\
\hline Constant & $\begin{array}{l}0.025^{* * *} \\
(0.01)\end{array}$ & $\begin{array}{l}0.022 * * * \\
(0.01)\end{array}$ & $\begin{array}{l}27.673 * * * \\
(8.33)\end{array}$ & $\begin{array}{l}28.889 * * * \\
(9.40)\end{array}$ & $\begin{array}{l}1100.000 * * * \\
(202.19)\end{array}$ & $\begin{array}{l}1446.301 * * * \\
(257.09)\end{array}$ \\
\hline Observations & 1425 & 1321 & 1425 & 1321 & 28 & 26 \\
\hline R-squared & 0.006 & 0.007 & 0.006 & 0.005 & 0.033 & 0.169 \\
\hline
\end{tabular}

OLS models with the application probability ( 1 and 2, linear probability models) and the number of minutes for subject we invited considering non-applicants as zero ( 3 and 4$)$ and for those who applied (5 and 6) as dependent variables. The reference group (Constant) is Voluntary. Robust standard errors are shown in parentheses

Significance levels $* * * p<.01, * * p<.05, * p<.10$

two-sided. See also the OLS regression in Table 3, model 1, which reports results from a linear probability model).

Now we take a closer look at the number of minutes of work time offered by the participants. The distribution of minutes offered in Waived Fee is again significantly different compared to Voluntary (3.07 and $27.67 \mathrm{~min}$, respectively; $p=.008$, MWU-test, two-sided). ${ }^{10}$ No such difference is observed between Voluntary and Certificate (27.67 and $35.07 \mathrm{~min}$, respectively; $p=.693$, MWU-test, two-sided). ${ }^{11}$ As also shown in the simple OLS regressions reported in Table 3 (model 3), the Waived Fee treatment reduces the number of minutes offered by about $89 \%$ from 27.67 to $3.07 \mathrm{~min}$, while the certificate had no significant effect.

\subsection{Monetary incentives}

Turning to the impact of monetary incentives, we can establish the following observation:

Observation 2 Once money is offered, increasing monetary incentives have a positive effect on the number of applications and the minutes of work offered. Relative to the Voluntary treatment even the highest hourly wage does not lead to a

\footnotetext{
${ }^{10}$ We treat every subject to whom we sent an email but who did not apply as a subject offering zero minutes of work.

11 The same results hold when we only compare the minutes offered by subjects that applied for help ( $p=.622$, MWU-test, two-sided). The sample size of two in Waived Fee is too small for any statistical test based on this measure.
} 
significantly higher number of applications but it does lead to a higher number of working minutes provided.

When we only consider the treatments in which hourly wages are paid, we find evidence of an increasing number of applications with an increase in monetary incentives according to a Jonckheere-Terpstra-test for ordered alternatives ( $p=.0205$, one-sided). A pairwise comparison of the $1.86 \%$ application rate (9 applications) in treatment 1 Euro with the $2.11 \%$ rate (10 applications) observed for the treatment 5 Euros shows no significant difference $(p=.48$, Fisher-test, onesided). When comparing the rates of application in treatments 1 Euro / 5 Euros with the $3.98 \%$ (19 applications) in the 10 Euros treatment, we find significant and sizable differences ( 1 Euro: $p=.038,5$ Euros: $p=.068$, Fisher-tests, one-sided).

The OLS regressions reported in Table 4 (model 1) complement our nonparametric findings. Reference group is the 10 Euros treatment as it led to the highest number of applications and the highest number of minutes of work time offered. Reducing the wage rate from 10 Euros to either 1 Euro or 5 Euros leads to a reduction of the application probability by roughly $50 \%$.

However, it also becomes clear that while the rate of applicants is somewhat smaller in the Voluntary treatment $(2.52 \%)$, the lack of any compensation shows no significant difference ( $p=.273$, Fisher-test, two-sided) to the 10 Euros treatment $(3.98 \%)$. This is also confirmed by the negative but non significant coefficient for

Table 4 Regressions for monetary incentives

\begin{tabular}{|c|c|c|c|c|c|c|}
\hline \multirow{3}{*}{$\begin{array}{l}\text { Independent } \\
\text { variables }\end{array}$} & \multicolumn{6}{|c|}{ Dependent variables } \\
\hline & \multicolumn{2}{|c|}{ Applications } & \multicolumn{2}{|l|}{ Minutes } & \multicolumn{2}{|l|}{ Minutes } \\
\hline & (1) & (2) & (3) & (4) & (5) & (6) \\
\hline 5 Euros & $\begin{array}{l}-0.019 * \\
(0.01)\end{array}$ & $\begin{array}{l}-0.018 \\
(0.01)\end{array}$ & $\begin{array}{l}-29.417 * \\
(15.78)\end{array}$ & $\begin{array}{l}-29.651 * \\
(16.93)\end{array}$ & $\begin{array}{l}-29.053 \\
(289.51)\end{array}$ & $\begin{array}{l}-56.061 \\
(293.04)\end{array}$ \\
\hline 1 Euro & $\begin{array}{l}-0.021^{* *} \\
(0.01)\end{array}$ & $\begin{array}{l}-0.023 * * \\
(0.01)\end{array}$ & $\begin{array}{l}-44.028 * * * \\
(15.69)\end{array}$ & $\begin{array}{l}-46.192 * * * \\
(16.77)\end{array}$ & $\begin{array}{l}-607.719 * * \\
(299.86)\end{array}$ & $\begin{array}{l}-566.667 * \\
(314.84)\end{array}$ \\
\hline Voluntary & $\begin{array}{l}-0.015 \\
(0.01)\end{array}$ & $\begin{array}{l}-0.013 \\
(0.01)\end{array}$ & $\begin{array}{l}-33.711 * * \\
(15.75)\end{array}$ & $\begin{array}{l}-33.953 * * \\
(16.92)\end{array}$ & $\begin{array}{l}-441.053 \\
(273.24)\end{array}$ & $\begin{array}{l}-455.658 \\
(278.51)\end{array}$ \\
\hline Female & & $\begin{array}{l}0.009 \\
(0.01)\end{array}$ & & $\begin{array}{l}6.286 \\
(11.95)\end{array}$ & & $\begin{array}{l}-186.052 \\
(217.86)\end{array}$ \\
\hline Constant & $\begin{array}{l}0.040 * * * \\
(0.01)\end{array}$ & $\begin{array}{l}0.036 * * * \\
(0.01)\end{array}$ & $\begin{array}{l}61.384 * * * \\
(11.14)\end{array}$ & $\begin{array}{l}61.114 * * * \\
(13.27)\end{array}$ & $\begin{array}{l}1541.053 * * * \\
(170.00)\end{array}$ & $\begin{array}{l}1679.693 * * * \\
(205.83)\end{array}$ \\
\hline Observations & 1911 & 1777 & 1911 & 1777 & 50 & 48 \\
\hline R-squared & 0.003 & 0.004 & 0.005 & 0.005 & 0.113 & 0.122 \\
\hline
\end{tabular}

OLS models with the application probability ( 1 and 2 , linear probability models) and the number of minutes for subject we invited considering non-applicants as zero (3 and 4) and for those who applied (5 and 6) as dependent variables. The reference group (Constant) is 10 Euros. Robust standard errors are shown in parentheses

Significance levels $* * * p<.01, * * p<.05, * p<.10$ 
the treatment dummy Voluntary in models 1 and 2 in Table 4 (where the Constant represents the baseline application rate under the 10 Euros treatment).

Hence, paying a slightly above standard hourly wage did not appear to contribute to a significant increase in the number of applicants relative to the announcement of a purely voluntary activity. The application rates both for the 1 Euro $(1.86 \%)$ and the 5 Euros $(2.11 \%$ ) treatment (even though lower) are also not significantly different from that under the Voluntary $(2.52 \%)$ treatment ( 1 Euro: $p=.516 ; 5$ Euro: $p=.83$, Fisher-tests, two-sided).

Again there is an increasing number of working minutes offered across the monetary treatments $(p=.019$, Jonckheere-Terpstra-test, one-sided). A pairwise comparison of the working minutes offered in treatment 1 Euro $(17.36 \mathrm{~min})$ with those offered in treatment 5 Euros $(31.97 \mathrm{~min})$ yields no significant difference ( $p=.763$, MWU-test, two-sided): When removing the zeros, i.e., within the group of applicants, the difference becomes marginally statistically significant $(p=.098$, MWU-tests, two-sided). Contrasting the working minutes in treatment 1 Euro / 5 Euros with the 10 Euros (61.38 minutes) treatment reveals significant differences (1 Euro: $p=.024,5$ Euros: $p=.047$, MWU-tests, one-sided). ${ }^{12}$ In Table 4 (model 3) we display the results of OLS regressions with working minutes as dependent variable. Given that money is offered, the minutes supplied vary nearly linearly in the wage rate (the minutes supplied are highly significantly different between the 1 Euro and 10 Euros condition while only marginally significantly different between the 5 Euro and 10 Euros condition). It is notable that with respect to the offered working time the announcement for a pure Voluntary service significantly (at the $5 \%$ level) reduced the number of minutes offered by about $50 \%$ relative to the 10 Euros treatment (27.67 and $61.38 \mathrm{~min}$, respectively). Hence, while paying money did not help to increase the number of applicants, it substantially raised the willingness to spend time once the payment exceeded a typical student reservation wage, which is at about 8.80 Euros at the University of Cologne.

However, when paying only a small compensation, using money seems to have led to a reduction of working minutes offered compared to the Voluntary treatment. While we are cautious with the observation that the reduction is not significant ( 1 Euro: $p=.482$, MWU-tests, two-sided), which could potentially be due to a lack of statistical power, the pattern is consistent with the existence of crowding-out effects of small monetary compensation reported by Gneezy and Rustichini (2000a). ${ }^{13}$

Finally, when we compare the number of applications in Waived Fee with the treatments with a monetary compensation, we find significantly fewer applications when the fee is waived than in all monetary treatments ( 1 Euro: $p=.064,5$ Euros:

\footnotetext{
12 Only taking into account the number of minutes of those subjects who actually applied for help confirms the observation of an increasing labor supply ( $p=.037$, Jonckheere-Terpstra-test, one-sided).

13 There are several interpretations for such crowding-out effects based on formal economic models. An interpretation of this result in light of Bénabou and Tirole (2006) is that weak monetary incentives reduce the signaling value of an application to demonstrate pro-social preferences. An interpretation in the spirit of Sliwka (2007) is that offering weak monetary incentives may reveal that volunteering without any monetary compensation is not the norm of behavior (hence, money has to be offered to attract applications). At the same time, the hourly wage is too small to attract applications that are driven by purely pecuniary motives.
} 
$p=.037,10$ Euros: $p=.0001$, Fisher-tests, two-sided). We also find that the amount of minutes offered by applicants is significantly lower in Waived Fee compared to the monetary treatments (1 Euro: $p=.038,5$ Euros: $p=.021,10$ Euros: $p=.001$, MWU-tests, two-sided). ${ }^{14}$

In the next section, we explain the results of an additional online-survey experiment that was set up to explore candidate explanations for this negative effect of the waived conference fee.

\section{Why is it harmful to mention the waived fee?}

When we compare the treatments without any monetary compensation, we find one rather surprising result, namely that mentioning the waived conferences fees induces substantial demotivating effects (Observation 1). There are several possible explanations for this finding, which we now discuss. First, by being promised that the conference fee will be waived, potential helpers may feel an obligation to actually attend the entire conference, which reduces their willingness to offer help. In the following, we refer to this explanation as the Obligation Hypothesis. Second, by mentioning the waived fee, potential helpers may become aware that a substantial budget is actually available and feel exploited when being offered no compensation (Exploitation Hypothesis). Possible explanations three and four rely on different mechanisms of crowding-out of intrinsic motivation by extrinsic rewards. The third explanation is that mentioning the waived fee leads to a framing effect as it induces potential helpers to focus on extrinsic rather than intrinsic motives, while the extrinsic reward actually looks rather weak (Framing Hypothesis). Finally, a fourth explanation could be that potential helpers might want to signal pro-sociality by helping the conference organizers. This may be difficult if others know that a conference fee is waived for volunteers. If the waived fee has only a small extrinsic value (as students typically are not willing to may such an amount of money to attend a scientific conference), the loss in image motivation may well exceed the extrinsic value of the fee. We refer to this explanation as the Signaling Hypothesis. Thus, in the latter two hypotheses, which are in the spirit of Bénabou and Tirole (2006), the waived fee may reduce the scope for signaling a pro-social motivation while at the same time not inducing a sufficiently strong extrinsic motive. ${ }^{15}$

\footnotetext{
14 Interestingly, comparing the total minutes offered between all non-monetary (Voluntary, Waived Fee, Certificate) to the total minutes offered in all monetary treatments, we observe no statistical significant difference considering all participants $(p=.216$, MWU-test, two-sided) and applicants exclusively ( $p=.156$, MWU-test, two-sided).

15 Another explanation could be that different types of helpers apply in different treatments. Therefore, after the conference we sent out emails with invitations to incentivized questionnaires asking participants for individual characteristics and personality traits, e.g., the surveys on human values by Schwartz (1992) or motives to volunteer by Clary et al. (1998). Analyzing the data from the questionnaire, no significant difference could be found between the six treatment groups - which may, however, be due to a lack of statistical power as the response rates of subjects who actually applied as a helper was only about $50 \%$.
} 
Having derived the above-mentioned four hypotheses as possible explanations for one key result of our field experiment, we decided to run an additional online survey experiment to shed more light on the underlying motives of the discouraging effect in the Waived Fee treatment. To do this, participants in the online survey experiment learned about the content of a letter offering a job at a conference and were asked about their perceptions about the respective invitation letter. We recruited two groups of subjects in order to elicit perceptions about the treatments Voluntary and Waived Fee from the field experiment. In each treatment of the online survey experiment, participants were shown one of the two job offers, i.e., they were shown the exact same text of the email sent out by the organizers of the conference in the field experiment. To avoid potential experimenter demand effects, our design differs from typical vignette studies in that we apply a between-subjects design where each student was asked about only one letter.

In both treatments, participants had to state the extent to which they agree with a number of statements. Our goal was to investigate whether and in which points outside observers differ in their own perceptions of the job announcement. In addition, we wanted to find out how a person who applied for the job in either of the two treatments is perceived. Therefore, we presented participants three different perspectives: First, we asked about possible personal reasons to reject the offered job (cluster I, 6 items). Here, the statements, i.e., the survey items, implied reasons to reject the offered job that were mainly derived from feelings of obligation (Obligation Hypothesis) or exploitation (Exploitation Hypothesis). Second, participants had to state the extent to which they agree with statements characterizing a person who accepted the offered job (cluster II, 24 items). By taking this perspective, the Framing and Signaling Hypotheses can primarily be addressed. Third, we asked participants about the offered job itself (cluster III, 6 items). Participants here had to state to what extent they agree to statements that relate to their personal feelings after accepting the job. The items were again chosen such that they address the four above-mentioned hypotheses. Participants had to rate the items on a seven-point Likert-scale measuring agreement with the respective statements, where 1 means "I strongly disagree" and 7 "I strongly agree". The full survey is reported in the Appendix in Table 5.

Participation in the online survey experiment was incentivized by offering 500 Euros to one randomly drawn subject. We sent out 3,494 emails asking students from a similar pool of subjects (students from the Faculty of Management, Economics and Social Sciences at the University of Cologne) to participate in survey experiment. In total, 180 students took part. In the following we go through each of the four hypotheses with respect to the data obtained from the two treatments of the online-survey experiment. We proceed in two steps. First, we provide exploratory evidence by testing responses to the individual items relevant for the different hypotheses against each other (see Table 5 in the Appendix). However this exploratory non-parametric assessment could be affected by a multiple testing concern as we test a high number of items against each other. Hence, for each of the item clusters we conduct a complementary factor analysis 
Table 5 Results of online survey experiment
Mean values per treatment for each item of reasons for rejecting the request for help, feelings after acceptance and perceptions of others that applied (1 strongly disagree to 7 strongly agree), Stars display significances from a one-sided Mann Whitney $\mathrm{U}$ test $* p<.1$, $* * p<.05, * * * p<.01$

\begin{tabular}{|c|c|c|c|}
\hline & \multicolumn{3}{|l|}{ Treatment } \\
\hline & Voluntary & & Waived fee \\
\hline \multicolumn{4}{|c|}{ I. Reasons for rejecting the request for help } \\
\hline Feeling of exploitation & 2.72 & & 2.73 \\
\hline Avoid obligation & 3.91 & $>* *$ & 3.43 \\
\hline Commitment & 3.39 & & 3.09 \\
\hline Not-interested in topic & 3.3 & & 3.2 \\
\hline Low benefits & 3.8 & & 3.81 \\
\hline Feeling of obligation & 3.49 & & 3.12 \\
\hline Being gullible & 2.7 & & 2.7 \\
\hline Exploitation by organizers & 2.85 & & 2.92 \\
\hline \multicolumn{4}{|c|}{ II. Perceptions of others that applied (These people are...) } \\
\hline Nice & 4.43 & & 4.38 \\
\hline Friendly & 4.44 & & 4.58 \\
\hline Helpful & 5.27 & & 5.03 \\
\hline Motivated & 5.64 & $>* *$ & 5.46 \\
\hline Socially responsible & 4.99 & & 4.79 \\
\hline Stupid & 2.07 & & 2.05 \\
\hline Exploitable & 2.64 & & 2.74 \\
\hline Easy to deceive & 2.60 & & 2.60 \\
\hline Superficial & 2.91 & & 3.04 \\
\hline Naive & 2.78 & & 2.74 \\
\hline Involved & 5.73 & & 5.68 \\
\hline Opportunistically & 3.74 & & 3.88 \\
\hline Pretentious & 2.92 & & 3.16 \\
\hline Status-oriented & 4.01 & $<* *$ & 4.49 \\
\hline Ambitious & 5.39 & & 5.25 \\
\hline Over-ambitious & 3.76 & & 3.80 \\
\hline Carrerists & 3.99 & & 3.93 \\
\hline Carrer-oriented & 4.93 & $<* *$ & 5.11 \\
\hline Curious & 5.31 & & 5.32 \\
\hline Interested & 5.45 & & 5.46 \\
\hline Diligent & 5.25 & & 5.31 \\
\hline Eager & 5.16 & & 5.14 \\
\hline Conscientious & 4.69 & & 4.64 \\
\hline Duitiful & 4.94 & $>* *$ & 4.70 \\
\hline \multicolumn{4}{|c|}{ III. Feelings after acceptance (Do you feel...) } \\
\hline Proud & 4.82 & & 4.65 \\
\hline Needed & 4.73 & & 4.54 \\
\hline Glad & 5.21 & & 4.91 \\
\hline Obligated & 5.21 & & 5.03 \\
\hline Exploited & 2.51 & & 2.46 \\
\hline Looking forward & 5.27 & & 5.14 \\
\hline
\end{tabular}


Table 6 Mean predicted factor scores

Treatments

Factor

Voluntary

Waived fee

I. Reasons for rejecting the request for help

\begin{tabular}{|c|c|c|c|}
\hline EXPLOITATION & -0.000076 & & -0.001981 \\
\hline OBLIGATION & 0.000308 & $>*$ & -0.201149 \\
\hline
\end{tabular}

NAIVETÉ

0.000129

0.028801

STATUS-ORIENTATION

0.000336

0.236155

Motivation

$-0.000183$

$-0.093583$

Dutifulness

0.000428

$-0.24263$

III. Feelings after acceptance

PRIDE

$-0.000276$

$-0.232293$

Stars display significances from a one-sided MWU-test $* p<.1, * * p<.05, * * * p<.01$ comparing the mean predicted factor scores between the treatments

(see Table 7 in the Appendix) of the survey data from the baseline setting in order to reduce the number of variables that are tested. ${ }^{16}$

For cluster I (asking about reasons for a rejection of the offer), the factor analysis reveals two underlying latent factors. The first of these can be linked to the degree of "Exploitation" and the second to the degree of "Obligation" to do something that may not be worth it (Factor loadings larger than 0.4 are reported in Table 7). For cluster II (asking for perceptions about individuals who decided to apply for a given letter), four factors are identified, namely one relating to "Naiveté", a second one capturing mere "Status orientation", a third one linked to the intensity of the "Motivation" and a fourth one capturing the feeling of "Dutifulness" of the candidates. Finally, in cluster III (asking for feelings after a potential acceptance of the job offer) one factor is identified referring to feelings of "Pride" and being needed. Hence, we altogether can measure seven different factors in our survey and test differences in the factor scores between the two treatments.

Table 6 reports mean predicted factor scores for the two treatments, including $p$ values testing the difference between the mean factor scores (MWU-tests, onesided).

\subsection{Obligation hypothesis}

If people in the Waived Fee treatment state the feeling of obligation to attend the conference as a more prominent reason for not applying compared to the Voluntary treatment, we would regard this as support for the obligation hypothesis. But, when asking for possible reasons for refusing the offered job, we find that participants apparently have stronger feelings of being obliged to attend the entire conference in

\footnotetext{
16 As is common procedure in the literature on survey design [see, for instance,Costello and Osborne (2005); Acock (2014, Chap. 12)], we consider factors with an Eigenvalue larger than 1.
} 
Voluntary than in Waived Fee, as they stress this feeling of obligation to a significantly stronger extent in the Voluntary treatment (Item: 'I do not want to feel obliged to participate at the complete conference', $p=.0285$, MWU-test, onesided). Moreover, we observe that applicants are perceived to be more dutiful in Voluntary than in Waived Fee (Item: 'These people are dutiful', $p=.08235$, MWUtest, one-sided). These observations are confirmed by contrasting the predicted factor scores under the two treatments (factor Obligation $p=.0877$, and factor Duty $p=.0257$, MWU-tests, one-sided). Hence, we find no evidence for the hypothesis that the waived fee creates a stronger feeling of obligation to attend the whole conference.

\subsection{Exploitation hypothesis}

The exploitation hypothesis suggests that participants are rated as more exploitable in the Waived Fee treatment than in the Voluntary treatment. A question regarding possible exploitative perceptions of the job offers was not answered differently between the two scenarios (Item: 'These people are exploitable', $p=.4911$, MWUtest, one-sided). Moreover, there are no different perceptions of feeling exploited between the two treatments (Item: 'I have the feeling that the conference organizers want to exploit me', $p=.3067$, MWU-test, one-sided). This is confirmed by the results of the factor analysis. While we identified a factor referring to feelings of exploitation, the factor scores were not significantly different in the two treatments ( $p=.4943$, MWU-test, one-sided).

\subsection{Framing and signaling hypotheses}

The framing hypothesis suggests that we would find differences in the participants' focus and their own direct attitudes towards the two offers. Mentioning the extrinsic "reward" of the waived fee might reduce the salience of intrinsic motivation. With respect to concerns about being able to signal pro-sociality in the Waived Fee treatment, our hypothesis is that people who actually applied under the waived fee are rated higher in terms of their extrinsic motives and lower in terms of their intrinsic motives. Although we cannot unambiguously differentiate between the two versions of the crowding-out explanation, our findings on the perceptions of somebody else accepting the job lend support to the signaling hypothesis. For instance, survey participants think that peers who accepted the offer are more motivated to work in the Voluntary as compared to the Waived Fee treatment (Item: 'These people are motivated', $p=.0434$, MWU-test, one-sided). No differences with respect to intensity of interest in the conference topic can be found (Item: 'These people are interested', $p=.4970$, MWU-test, one-sided). Furthermore, participants think that others who help in Waived Fee are more status-oriented (Item: 'These people are status-oriented', $p=.0102$, MWU-test, one-sided) and more career-concerned (Item: 'These people are career-concerned.', $p=.0741$, MWU-test, one-sided) than in Voluntary.

When comparing the relevant factors, we do not find treatment differences in the factor scores relating to the topic of motivation ( $p=.22$, MWU-test, one-sided). 
However, we find a significant difference in the factor relating to "status orientation": Applicants under the Voluntary treatment are perceived to be significantly less status-concerned than the ones under Waived Fee treatment ( $p=.0465$, MWU-test, one-sided). We also detect a significantly more intense perceived sense of dutifulness under the Voluntary than under the Waived Fee treatment ( $p=.0257$, MWU-test, one-sided) as well as a greater sense of pride ( $p=.0896$, MWU-test, one-sided).

Hence, these observations support the idea that participants were deterred from applying at the conference as volunteering under the Waived Fee condition implies (and signals) a rather extrinsic status orientation and lower intrinsic motivators, such as pride in helping the university or or feelings of duty. In line with Bénabou and Tirole 2006), the externally visible (and relatively weak) extrinsic motivator apparently reduces the scope to signal an intrinsic motivation by helping the conference organizers and thus backfires.

\section{Conclusion}

Our field experiment reveals some intricate patterns in the motivation to volunteer. The results from the monetary incentives treatments are generally in line with neoclassical reasoning as increasing hourly wages shows positive effects on the number of job applications and on the working time offered. However, when comparing these results with a treatment without any monetary compensation, the number of applications could not be increased by offering money and may have even been reduced when hourly payments are small. However, once the payment offered exceeds the reservation wage, it also leads to a larger overall labor supply. A direct implication of this result is that if the pool of potential volunteers is sufficiently large and it suffices that each volunteer provides a smaller amount of working time, not offering money may be preferable even in the absence of budget constraints. However, when the applicant pool is not large enough, paying wages above the reservation wage still helps to increase the overall labor supply. ${ }^{17}$

The most striking result of our field experiment is that by mentioning a specific non-monetary extrinsic motivator, the waived conference fee induces substantial negative effects on both the number of applications and working hours offered.

Our complementary survey experiment suggests that helpers' status-concerns are perceived to be lower when they participate voluntarily compared to when the waived fee is mentioned. Therefor, candidates seem to be able to (self-)signal higher intrinsic motivation when the waived fee is not highlighted. Our findings reveal that when looking for volunteers it is essential to consider potential detrimental effects of seemingly useful rewards, such as waiving a fee. Further study of the conditions

\footnotetext{
${ }^{17}$ For our purposes, for instance, we needed 86 hours of help. Given the observed application frequency and the average working time offered, it is necessary to contact at least 190 students $(=86 / .0252 \cdot 18 \mathrm{~h})$ in the Voluntary treatment to receive sufficient support in expected terms. When offering money, e.g., in the 10 Euros treatment, we only would have needed an applicant pool of only 85 students $(=86 / .04 \cdot 25 \mathrm{~h})$ to satisfy the requirements of the conference.
} 
under which such crowding-out effects of intrinsic motivation are prevalent in the hiring of voluntary helpers would be an interesting topic for future research.

Acknowledgments We are grateful to Thomas Lauer, Oliver Gürtler, Christian Ruppert and Julia Stauff for their help in conducting the experiment. We also thank the Editor, two anonymous referees, Max Bazerman, Oleg Badunenko, Antonio Filippin, Andrew Kinder, Steve Levitt, John List, Susanne Neckermann, Gerhard Riener, Alessandro Saia, and seminar participants at University of Chicago, University of Paderborn and EALE Conference 2014 (Ljubljana) for helpful comments. Financial support from the Deutsche Forschungsgemeinschaft through grant TP3 Design of Incentive Schemes within Firms: Bonus Systems and Performance Evaluations (sub-project of the DFG-Forschergruppe Design and Behavior) is gratefully acknowledged.

\section{Appendix}

\section{Invitation email}

Subject: Volunteers for a conference

Dear $\langle$ Name inserted $\rangle$,

From 12th to 15th of September 2012 the conference of the Economic Science Association (ESA) is taking place at the University of Cologne. Over 200 economists from all over the world get together to talk about current findings from the field of behavioural economics. Besides many interesting speeches, there are presentations from international elite researchers (i. a. Max Bazerman from Harvard Business School). You can find more details on the conference homepage www.esa.uni-koeln.de. For the preparation and procedure of the conference we are looking for volunteers, who support us in the organization before and during the conference. During the times you are not working as a volunteer you can attend interesting lectures and discussions.

\{Voluntary: $\}$

\{Certificate: At the end of the conference we hand a certificate out to you.

\{Waived Fee: The participation fee which you are exempted from would be about $320 €$.

$\{1$ Euro: Per working hour you get $1 €$.

$\{5$ Euros: Per working hour you get $5 €$. $\}$

$\{10$ Euros: Per working hour you get $10 €$. $\}$

In case we aroused your interest you can apply online and without much expenditure of time under this link. You can also indicate on which days and how many hours you would like to work for us: You can find the application here.

Yours sincerely,

Prof. Dr. Bernd Irlenbusch \& Prof. Dr. Dirk Sliwka

\section{References}

Acock, A. (2014). A gentle introduction to stata. College Station, TX: STATA Press.

Akerlof, G. A., \& Kranton, R. E. (2000). Economics and identity. The Quarterly Journal of Economics, 115(3), 715-753. 
Al-Ubaydli, O., \& Lee, M. (2011). Can tailored communications motivate environmental volunteers? A natural field experiment. American Economic Review, 101(3), 323-328.

Andreoni, J. (1998). Toward a theory of charitable fund-raising. Journal of Political Economy, 106(6), 1186-1213.

Ariely, D., Bracha, A., \& Meier, S. (2009). Doing good or doing well? Image motivation and monetary incentives in behaving prosocially. The American Economic Review, 99(1), 544-555.

Bénabou, R., \& Tirole, J. (2003). Intrinsic and extrinsic motivation. The Review of Economic Studies, 70(3), 489-520.

Bénabou, R., \& Tirole, J. (2006). Incentives and prosocial behavior. American Economic Review, 96(5), $1652-1678$.

Bradler, C., Dur, R., Neckermann, S., Non, A., 2013. Employee recognition and performance: A field experiment. Tinbergen Institute Discussion Paper 038/VII.

Clary, E. G., Snyder, M., Ridge, R. D., Copeland, J., Stukas, A. A., Haugen, J., et al. (1998). Understanding and assessing the motivations of volunteers: A functional approach. Journal of Personality and Social Psychology, 74, 1516-1530.

Costello, A. B., \& Osborne, J. W. (2005). Best practices in exploratory factor analysis: Four recommendations for getting the most from your analysis. Practical Assessment Research \& Evaluation, 10(7), 1-9.

Deci, E., \& Ryan, R. (1985). Intrinsic motivation and self-determination in human behavior. New York: Plenum Press.

Frey, B., Götte, L., 1999. Does pay motivate volunteers? Working Paper-Institute for Empirical Economic Research - University of Zurich.

Gneezy, U., Meier, S., \& Rey-Biel, P. (2011). When and why incentives don't work to modify behavior. Journal of Economic Perspectives, 25(4), 1-21.

Gneezy, U., \& Rustichini, A. (2000a). A fine is a price. Journal of Legal Studies, 29(1), 1-17.

Gneezy, U., \& Rustichini, A. (2000b). Pay enough or don't pay at all. The Quarterly Journal of Economics, 115(3), 791-810.

Harrison, G. W., \& List, J. A. (2004). Field experiments. Journal of Economic Literature, 42(4), 1009-1055.

Holmström, B. (1999). Managerial incentive problems: A dynamic perspective. The Review of Economic Studies, 66(1), 169-182.

Kosfeld, M., \& Neckermann, S. (2011). Getting more work for nothing? Symbolic awards and worker performance. American Economic Journal: Microeconomics, 3, 86-99.

Lacetera, N., Macis, M., \& Slonim, R. (2012). Will there be blood? Incentives and displacement effects in pro-social behavior. American Economic Journal: Economic Policy, 4, 186-223.

Linardi, S., \& McConnell, M. A. (2011). No excuses for good behavior: Volunteering and the social environment. Journal of Public Economics, 95(5-6), 445-454.

Mellström, C., \& Johannesson, M. (2008). Crowding out in blood donation: Was Titmuss right? Journal of the European Economic Association, 6(4), 845-863.

Menchik, P. L., \& Weisbrod, B. A. (1987). Volunteer labor supply. Journal of Public Economics, 32(2), $159-183$.

Schwartz, S. H. (1992). Universals in the content and structure of values: Theoretical advances and empirical tests in 20 countries. Advances in Experimental Social Psychology, 25(1), 1-65.

Sliwka, D. (2007). Trust as a signal of a social norm and the hidden costs of incentive schemes. American Economic Review, 97(3), 999-1012.

Titmuss, R. (1970). The gift relationship: From human blood to social policy. New York: The New Press. 